\title{
The Troubled Transformation of Britain's National Health Service
}

\author{
Rudolf Klein, M.A.
}

If births can be difficult, so can rebirths. The creation of Britain's National Health Service (NHS) in 1948 provoked political friction and medical opposition. Its current transformation is also proving contentious. In the first few months of 2006, the word "crisis" and the NHS were reunited in newspaper headlines - a coupling familiar throughout the history of the service. NHS trade unions staged protests as staff were laid off; patients worried as media stories about hospitals delaying treatment or economizing on drugs multiplied; the chief executive of the NHS took early retirement; and the prime minister rushed to the defense of the government's policies. What made this spectacle both puzzling and revealing was the disjunction between cause and effect. The cause was a fiscal hiccup: a relatively trivial deficit in the NHS's accounts. The effect was political drama. Just when the government's radical plans for the NHS appeared to be heading toward success - with extra billions of funding flowing in, waiting times dropping, and quality improving - doubt, skepticism, and hostile criticism crept in. Was the prime minister right in claiming that the disruption caused by a fiscal hiccup was no more than a transitional blip, inevitable when carrying out an ambitious plan of reform? Alternatively, did it indicate weaknesses in the way the government had designed and implemented its policies? Was the government going too far too fast in reinventing the NHS?

In what follows, I address these and other questions. First, I outline the government's program for transforming the NHS - the new model that is gradually emerging. Second, I analyze the nature of the "crisis" and what it tells us about the government's policies and the process of implementing them. In all this, the focus is on the NHS in England; Scotland and Wales have followed somewhat divergent paths since being granted a degree of self-government.
THE EMERGENT MODEL

The NHS's fiscal troubles were all the more perplexing for the British public - as well as foreign spectators - because they offered the spectacle of famine amidst plenty. At the beginning of 2000, Prime Minister Tony Blair pledged large increases in funding for the NHS that were designed to bring health care spending up to the level of that in other western European countries. In fiscal year 1999, spending on the NHS was $£ 40,755$ billion (approximately U.S. $\$ 75$ billion). By fiscal year 2005, the figure had risen to $£ 71,733$ billion ( $\$ 132$ billion). And by fiscal year 2007 , it is planned to increase to $£ 86,500$ billion (almost $\$ 160$ billion). ${ }^{1}$ The sustained annual rate of increase of 7.3 percent above inflation is more than double the average in previous decades and is unprecedented in the history of the NHS. So whatever the NHS's problems, they cannot be laid at the door of fiscal stringency - the explanation invariably invoked in the past whenever the word "crisis" surfaced in the headlines. If problems exist, as they do, they reflect the tensions and stresses involved in carrying out the most radical and ambitious program of change since the launch of the NHS in 1948.

The Labour government that took office in 1997 spent its first five years strengthening the NHS's command-and-control structure. ${ }^{2}$ As a tax-funded service, the NHS had always been more centralized than other health care systems. But centralization was compounded as ministers sought to prod the NHS into modernizing itself. Performance indicators multiplied, as did the protests against their proliferation. National service frameworks, templates for the design and delivery of health care, were promulgated. The Department of Health and its ministers were ever more active, intervening to chastise lagging performers. A hyperactive government swamped 
the NHS with initiative after initiative, ranging from setting targets for waiting times to establishing teams to inspect hospitals for cleanliness. But waiting lists stubbornly persisted, as did the gaps in performance between the most efficient and the least efficient providers. And given that under the British system of parliamentary accountability, ministers were answerable for every dropped bedpan in the NHS, political embarrassment followed: a command-and-control system meant the centralization of blame.

A damascene conversion followed, as ministerial frustration increased. By 2002, ministers had became convinced that the answer was to decentralize and to insulate themselves from political exposure to the day-to-day problems of the NHS. Step by step, they moved toward a new model of the NHS. This represented a move from "a politician-led NHS to a patient-led NHS," to quote from the government's summary of its reform program. ${ }^{3}$ Incentives are to replace commands: the NHS is to be a "self-improving" system in which performance is driven not by ministerial fiat but by a combination of patients' choice, money following the patient, and competition among a diversity of providers. In effect, Prime Minister Blair is introducing a more radical and sophisticated version of the mimic market introduced by former Prime Minister Margaret Thatcher's Conservative administration in 1991, which the Labour Party (as well as the British Medical Association) denounced at the time and repudiated on taking office. The new model is still in the process of being implemented, and at present it coexists with the command-and-control structure built up in earlier years. The NHS landscape therefore represents an often confusing mix of different, overlapping policy strata. But the main elements in the government's strategy are clear enough. ${ }^{4}$ They can be set out under five headings.

\section{INCREASING CAPACITY}

From the start, the government realized that increasing the capacity of the NHS would have to be the first step in any modernization program. If waiting lists and waiting times - the most obvious symbols of the NHS's shortcomings, if not necessarily the most important ones - were to be cut, then more doctors, nurses, and other staff would be needed. New medical schools were set up; a recruitment drive abroad was launched.
Between 1999 and 2004, the number of NHS doctors increased by 25 percent. But it was not enough. Enter the private sector. The NHS increased the level of activity - predominantly elective surgery - contracted from existing private providers. This increase did not, however, add to the total available medical personnel, given that it was NHS consultants who performed the operations in their spare time. The next step was to invite new providers to set up shop in England, on the condition that they brought in their own clinical labor force. A number of Independent Treatment Centers, which provide elective surgery and diagnostic services, were set up. At the same time, the government relied increasingly on Private Finance Initiative schemes for building new hospitals and refurbishing old ones: under these schemes, the private sector finances, builds, and maintains the hospitals in question - transactions that do not appear in the Treasury's accounts and have therefore liberated the NHS from the tight control on capital spending that in the past made its hospitals a byword for shabbiness. The notion that private interests could be made to serve public ends, which is revolutionary in terms of Labour's traditional beliefs, had become firmly established. With it came acceptance also of a plurality of providers.

\section{POWER TO THE PERIPHERY}

The government's first step was to stress the role of the Primary Care Trusts, the 300-odd organizational bodies responsible both for providing general-practitioner and other services and for purchasing hospital care for their geographic populations. Some 85 percent of NHS funding now flows through these trusts. In theory, it is their responsibility to decide how the money is spent; in practice, given central directives, the trusts have come to understand that freedom lies in the knowledge of necessity.

A second step came with the introduction of a new organizational status for NHS providers. Hospital providers are now eligible to become Foundation Trusts if they meet certain financial and other criteria. So far, 40 Foundation Trusts have been approved. This status gives providers considerable autonomy in managing their affairs and greater freedom than they previously had to raise capital. In theory, the Foundation Trusts are accountable to the local communities they serve: their governing boards are elected 
partly by local people and partly by the hospital staff. $^{5}$ In practice, given that the governing boards have little power, the effective line of accountability runs to a newly created regulator, called Monitor. Crucially, however, it stops there. Ministers are no longer answerable to Parliament for what happens in a provider hospital after it has been transformed into a Foundation Trust.

\section{HANDS-OFF CONTROL}

Monitor is not the only regulator whose role in the new model is to insulate ministers. The Department of Health has issued national standards against which the quality of care is to be assessed. ${ }^{6}$ An independent regulator, the Healthcare Commission, is responsible for carrying out the assessment. Finally, another regulator, the National Institute for Clinical Excellence, is charged with determining whether, and how, new drugs and procedures are to be used in the NHS, thereby substituting technical criteria (notably the relative cost-effectiveness of different drugs and procedures) for political decisions about rationing.

\section{PATIENTS' CHOICE}

Choice is a key element in the transformation of the NHS into a "patient-led" service. Since December 2005, patients have been entitled to a choice among four providers for elective care, and by 2008 , there is to be a free choice of referral to any provider, whether one within the NHS or a private one, who meets the standards and prices of the NHS. Further, patients are being given more information than in the past to assist them in making their choice. For example, the Healthcare Commission launched a Web site this year giving survival rates for heart surgery, both according to hospital and according to individual surgeon.

\section{PAYMENT BY RESULTS}

Driving the new system will be "payment by results" - that is, money following patients (to be distinguished sharply from the performancerelated contract for general practitioners, which is designed to reward them not for the quantity of work done but for its quality). Uniform national prices for specific interventions and conditions, first cousins of the diagnosis-related groups long used in the United States, are gradually being introduced by the Department of Health. Hitherto, Primary Care Trusts have agreed on block contracts with hospital providers, specifying the expected volume of activity - a process of bargaining that usually offers only a weak challenge to the prices charged by providers. In the future, as the new system begins to "bite," this situation will change: rewards will be precisely calibrated to the work done according to the national schedule of payments. The assumption - key to the new model - is that payment by results will spur providers to increase efficiency and give them an incentive to shape their services according to patients' preferences.

All the elements of the new model are thus in place, even though implementation is still patchy. But it must be stressed that this model is designed to exploit the dynamics of the market (in its emphasis on patients' choice, payment by results, and competition) but not to create a market in health care - hence my characterization of it as a "mimic" market. The NHS remains a tax-funded service providing comprehensive health care to the entire population, free at the point of delivery (charges for prescriptions for drugs excepted). Health care continues to be allocated according to need, as defined by medical professionals, not according to the capacity to pay. The change is in the means, not the aims: market dynamics are to be harnessed in the service of equity and social solidarity. To talk of the "privatization" of the NHS, as some traditionalists do, is therefore nonsense.

CRISIS OR BLIP?

This, then, is the background of the epidemic of crisis headlines in the media, noted at the beginning of this article. The crisis was prompted by the realization that the NHS was heading for a deficit in fiscal year 2005, ending in April 2006. Estimates of the threatened deficit fluctuated: the government put it at $£ 700$ million (U.S. $\$ 1.29$ billion), whereas independent analysts suggested that it might top $£ 1$ billion (U.S. $\$ 1.8$ billion). Even given the more pessimistic estimates, it was a drop in the ocean of NHS spending: somewhere between 1 percent and 1.5 percent of the total budget. However, the government saw the deficit as an example of the kind of fiscal indiscipline and poor management that it was determined to stamp out in the new model of the NHS, insisting that provider trusts and Primary Care Trusts should eliminate their excess 
spending and sending in turnaround teams to right their finances. The pain of forced retrenchment was all the greater because it fell on a minority of provider trusts - fewer than 10 percent of them, according to ministers, although independent analysts put the figure higher. Forcing the necessary savings inevitably brought about the staff cuts (an estimated 7000 jobs lost) and canceled operations that fueled the headlines. End-of-fiscal-year economies were nothing new in the history of the NHS. The new, rather shocking element was that the cuts were being made yet again at a time when the NHS was seemingly awash with money - hence the talk of crisis.

It was, of course, nothing of the sort. Rather, the cuts were an example of fiscal shock therapy producing short-term pain with the expectation of long-term improvement in the performance of the NHS. The NHS has long offered a paradox: a combination of strong collective fiscal discipline and considerable fiscal laxity when it came to individual units within it. It has been the envy of the world in terms of its ability to contain spending within the budgets set every year, even while allowing individual trusts to accumulate large deficits. This situation has been achieved through a complex system of brokerage whereby trusts in deficit have been allowed to borrow from trusts in surplus. In effect, the accounts have been fudged, in order to protect the weak and avoid turbulence. If the new model of the NHS is to work as intended - if efficiency is to be rewarded instead of inefficiency being cushioned — this juggling clearly had to stop.

The strategy is politically risky, as the outcry during the past months has shown. Why then have ministers pursued it? The NHS has undoubtedly improved and continues to do so. When in April 2006 Patricia Hewitt, the Secretary of State for Health, told a conference of nurses that the NHS had enjoyed its best year ever, she was forced to leave the podium by the jeering. But she was right. The indicators point in the right direction. ${ }^{7}$ Waiting lists are down, from a peak of more than 1.3 million in 1998 to just over 1 million by 2002 , and they were below 800,000 by the end of 2005 (Fig. 1). More important, the time spent on waiting lists has been reduced: whereas almost a quarter of all those on the lists at the beginning of 2002 had been waiting for more than five months, by March 2006 no one had been waiting that long. Similarly, death rates for cancer have decreased, even though the number of people who have received a diagnosis of cancer has increased; the death rate per 100,000 population has shown a steady decline, falling from 141.2 between 1995 and 1997 to 121.6 in 20022003. The treatment of patients with heart attacks with clot-dissolving drugs has accelerated and improved: the number of prescriptions written for lipid-regulating drugs rose from 9 million in 1999-2000 to over 34 million in 2005, and mortality from circulatory disease per 100,000 population fell from 141 in 1997-1998 to 96.7 in 2002-2003. The litany of success could be extended.

The picture, however, is not consistently or uniformly bright: for example, services for the mentally ill and the elderly leave much to be desired. ${ }^{8}$ Similarly, the implementation of policy initiatives designed to change the pattern of the delivery of services has proved more difficult than the government expected. More important still in explaining the impatient desire of ministers to push ahead with reengineering the NHS is the evidence that the rate of improvement in performance is not commensurate with the rate at which extra funds are flowing into the NHS, and that the gap between the best-performing and worst-performing providers persists. For example, a study of day surgery that showed that the most efficient 10 percent of units used their dedicated operating theaters for more than 75 percent of the time available, whereas the least efficient 10 percent used them for less than 35 percent of the time available, concluded that "Across the whole of England, there appeared to be a capacity to do 46 percent more day surgery cases in existing day surgery theaters" by achieving the level of efficiency of the upper quartile. ${ }^{9}$ No wonder, then, that ministers want to push on with their program of "creative destruction," as it has been called by the former head of the Department of Health's Strategy Unit. ${ }^{10}$

Those at the receiving end of such creative destruction have, not surprisingly, a rather different view of the matter. The oscillations of policy over the past decade have severely tested the capacity of NHS managers to absorb and adapt to change; medical morale remains brittle, as doctors see their status and autonomy threatened by a regime of inspection and regulation. Managers and professionals alike see themselves as 


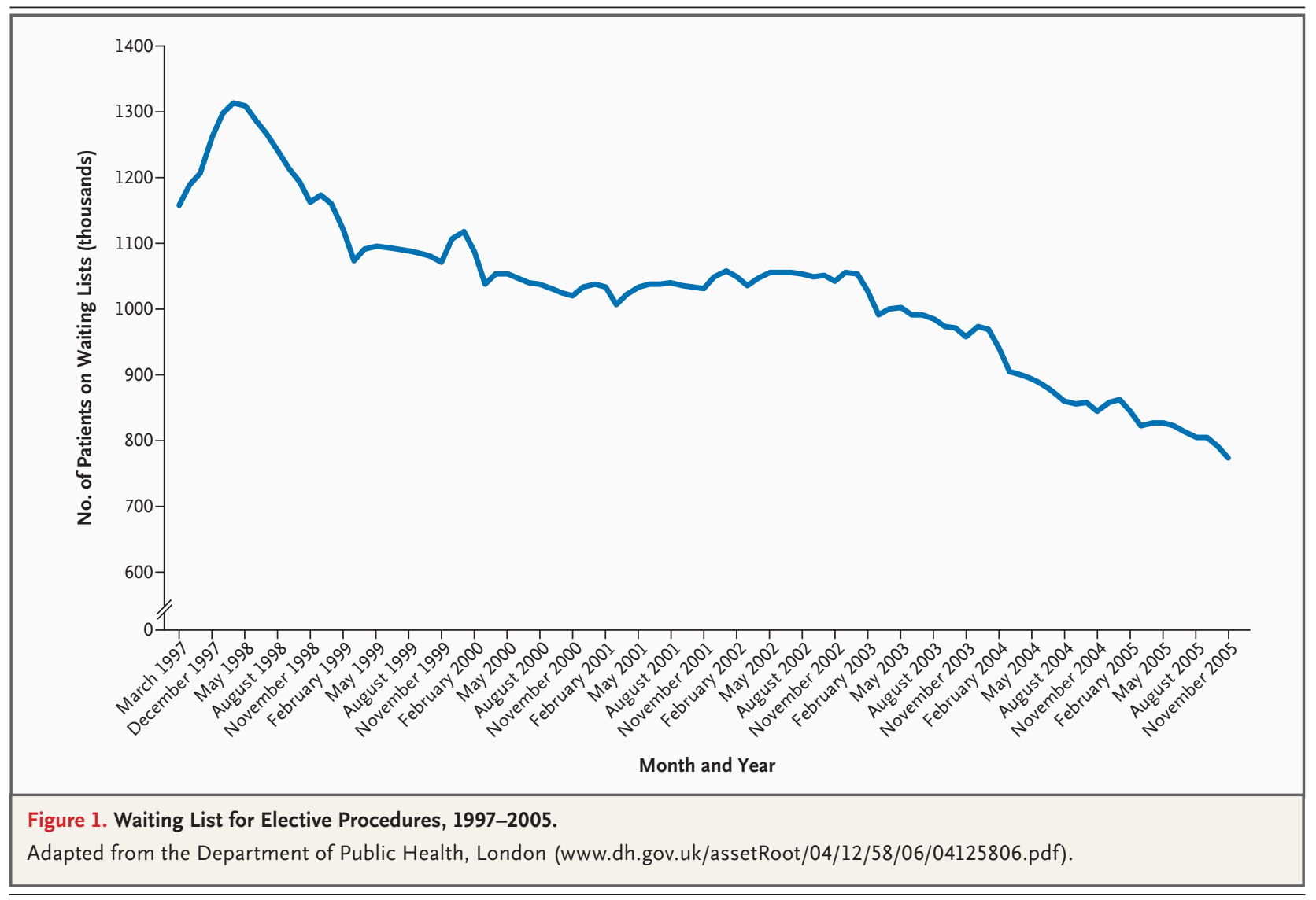

victims of ministers in a hurry, having to take the blame for the government's miscalculations. So for example, half the extra money flowing into the NHS during the past two fiscal years has been absorbed by cost increases, rather than by an expansion or improvement in services ${ }^{11}$ - hence the disappointing productivity performance. Driving much of the cost increases have been all-round increases in the pay of NHS staff. In particular, the national contracts for general practitioners and consultants introduced in 2004 have proved to be much more expensive than the government anticipated. British doctors are now the best paid in Europe.

It is not clear, however, just how much the NHS has gained in return for the investment of several billion pounds. In the case of general practitioners, the new contract links earnings to performance: their pay is linked to 76 indicators of quality, such as the quality of records and the proportion of patients whose blood pressure is recorded annually. In the case of consultants, the new contract clarifies their accountability for work done. However, it is difficult to resist the conclusion that "The pay rise has been so generous that hospital doctors and general practitioners can work fewer hours and still be better off financially - so in effect, the NHS is paying more for less." 12

POLICY TENSIONS AND STRAINS

There are other tensions between different strands of policy. The Private Finance Initiative building program has certainly helped to transform the quality of NHS buildings. But it has also locked the trusts involved into 30-year contracts with the private operators. Yet if the government succeeds in its policies for shifting care into the community, many of the buildings financed by the Private Finance Initiative could well become redundant long before the expiration of the contracts. But will the desired shift take place? "Payment by results" gives providers an incentive to maximize activity. One outcome could therefore be an increase in hospital activity, as 
providers increasingly market their services aggressively.

If hospitals have an incentive to drum up business, how is overall demand to be contained? The government, as already noted, has emphasized the role of the Primary Care Trusts, which are responsible for contracting services from hospital providers. It is currently planning a radical cut in their number, in the hope that fewer, larger Primary Care Trusts will also mean managerially more effective ones. However, moving from contracts for a specified volume of activity (the past pattern) to payment by results raises questions about the ability of even well-managed Primary Care Trusts to control the overall level of demand. It is not these Trusts that decide which patients to refer to hospitals for what treatment. It is general practitioners who do so which is why the government has revived generalpractitioner fundholding, originally introduced by the Thatcher government. General practitioners will once again be encouraged to opt for fixed budgets, out of which to pay for the services received by their patients. The assumption is that the general practitioners will incorporate budgetary constraints into the advice they give patients about how to exercise choice, with a strong incentive to choose cheaper options such as care in the community. Given such a transfer of money and power to the general practitioners, it is unclear how even the newly enlarged Primary Care Trusts can be expected to manage demand and cut the rates of referral to hospitals, as they are now being urged to do by ministers. ${ }^{13}$

The case of payment by results illustrates another challenge faced by the government: the technical and administrative difficulties of translating policy into practice. The national schedule of payments by results has been revised in the face of complaints about how it was set in the first place, as has the timetable for introducing it, and there is increasing pressure for the government to hand the task to an independent regulator. None of this is surprising. All countries that have introduced payment according to results have run into teething troubles, with unexpected or perverse results. What is surprising in this case, as in many others, is that the government did not anticipate the implementation problems and allow for them in its timetable for change - hence the criticism that the government is going too far, too fast.
But here ministers are in a dilemma. Their trinitarian model - competition, patients' choice, and payment by results - is based on the assumption that the interaction of the three elements will produce the dynamism required for greater efficiency and responsiveness. The logic of the model - which is based on classic economic theory - is tight and clear-cut. Introducing it on the installment plan, let alone modifying any part of its design, would therefore be rather like setting out to convert a horse and buggy into a modern automobile and ending up with a car drawn by horses. This is precisely what happened to the Conservative Party's attempt in the early 1990s to introduce a mimic market: when the dynamics of the market threatened to create turbulence, by forcing hospital closures, the government retreated. Given that the destructive part of the Blair government's package is likely to have more immediate political visibility than the creative element - by forcing painful change, such as hospital closures, thereby uniting NHS professionals and the public in protest - it is impossible to be sure that the new model can ever be fully implemented, however seductive its logic may be in theory.

So the Blair government is engaged in a double gamble. The first gamble is that the rate of improvement in efficiency produced by the new model will balance any increase in the demands on the NHS generated by the model. The second is that this balance will come in time for the government to reduce the rate of growth in the NHS's budget when its present commitment to high spending ends with fiscal year 2007. If by then there is no balance between efficiency gains and increased demands, between destruction and creation, the political reaction is likely to justify the invocation of crisis in a way that recent events certainly do not.

No potential conflict of interest relevant to this article was reported.

From Bath University, Bath, the London School of Economics and the London School of Hygiene, London - all in the United Kingdom.

1. Department of Health. Departmental report 2005. London: Stationery Office, 2005. (Series no. CM 6524.)

2. Klein R. The new politics of the NHS: from creation to reinvention 5th ed. Oxford, England: Radcliffe Medical Press, 2006.

3. Health reform in England: update and next steps. London: Department of Health, December 2005. (Accessed July 6, 2006, at http://www.dh.gov.uk/assetRoot/04/12/27/04124727.pdf.)

4. Stevens S. Reform strategies for the English NHS. Health Aff (Millwood) 2004;23(3):37-44. 
5. Day P, Klein R. Governance of foundation trusts: dilemmas of diversity. London: Nuffield Trust, 2005.

6. National standards, local action: health and social care standards and planning framework 2005/06-2007/08. London: Department of Health, 2004.

7. Chief Executive's report to the NHS: December 2005. London: Department of Health, 2005.

8. State of healthcare report 2005. London: Healthcare Commission, July 18, 2005. (Accessed July 6, 2006, at http://www. healthcarecommission.org.uk/nationalfindings/

stateofhealthcare.cfm.)
9. Acute hospital portfolio (AHP) review: day surgery. London: Healthcare Commission, July 2005.

10. Ham C. Creative destruction in the NHS. BMJ 2006;332: 984-5.

11. Appleby J, Harrison A. Spending on health care: how much is enough? London: King's Fund, February 2006.

12. Maynard A, Street A. Seven years of feast, seven years of famine: boom to bust in the NHS? BMJ 2006;332:906-8.

13. Clews G. PCTs ordered to slash GP referral rates. Health Service Journal. April 13, 2006:7.

Copyright (c) 2006 Massachusetts Medical Society. 